OPEN ACCESS

Edited by:

Rafael Linden,

Federal University of Rio de

Janeiro, Brazi

Reviewed by:

Raffaele Dubbioso,

Federico II University Hospital, Italy

Pratik Yashvant Chhatbar,

Duke University, United States

*Correspondence:

Anna Maria Cortese

annamaria.cortese@hsancamillo.it

Specialty section:

This article was submitted to

Neurodegeneration,

a section of the journal

Frontiers in Neuroscience

Received: 25 August 2021

Accepted: 07 October 2021 Published: 03 November 2021

Citation:

Cortese AM, Cacciante L,

Schuler A-L, Turolla A and Pellegrino G (2021) Cortical Thickness of Brain Areas Beyond Stroke Lesions and Sensory-Motor Recovery: A Systematic Review.

Front. Neurosci. 15:764671. doi: 10.3389/fnins.2021.764671

\section{Cortical Thickness of Brain Areas Beyond Stroke Lesions and Sensory-Motor Recovery: A Systematic Review}

\author{
Anna Maria Cortese ${ }^{1 *}$, Luisa Cacciante ${ }^{1}$, Anna-Lisa Schuler ${ }^{2}$, Andrea Turolla ${ }^{1}$ and \\ Giovanni Pellegrino ${ }^{2}$ \\ ${ }^{1}$ Laboratory of Rehabilitation Technologies, San Camillo Istituto di Ricovero e Cura a Carattere Scientifico, Venice, Italy, \\ ${ }^{2}$ Laboratory of Clinical Imaging and Stimulation, San Camillo Istituto di Ricovero e Cura a Carattere Scientifico, Venice, Italy
}

Background: The clinical outcome of patients suffering from stroke is dependent on multiple factors. The features of the lesion itself play an important role but clinical recovery is remarkably influenced by the plasticity mechanisms triggered by the stroke and occurring at a distance from the lesion. The latter translate into functional and structural changes of which cortical thickness might be easy to quantify one of the main players. However, studies on the changes of cortical thickness in brain areas beyond stroke lesion and their relationship to sensory-motor recovery are sparse.

Objectives: To evaluate the effects of cerebral stroke on cortical thickness (CT) beyond the stroke lesion and its association with sensory-motor recovery.

Materials and Methods: Five electronic databases (PubMed, Embase, Web of Science, Scopus and the Cochrane Library) were searched. Methodological quality of the included studies was assessed with the Newcastle-Ottawa Scale for non-randomized controlled trials and the Risk of Bias Cochrane tool for randomized controlled trials.

Results: The search strategy retrieved 821 records, 12 studies were included and risk of bias assessed. In most of the included studies, cortical thinning was seen at the ipsilesional motor area (M1). Cortical thinning can occur beyond the stroke lesion, typically in regions anatomically connected because of anterograde degeneration. Nonetheless, studies also reported cortical thickening of regions of the unaffected hemisphere, likely related to compensatory plasticity. Some studies revealed a significant correlation between changes in cortical thickness of M1 or somatosensory (S1) cortical areas and motor function recovery.

Discussion and Conclusions: Following a stroke, changes in cortical thickness occur both in regions directly connected to the stroke lesion and in contralateral hemisphere areas as well as in the cerebellum. The underlying mechanisms leading to these changes in cortical thickness are still to be fully understood and further research in the field is needed.

Systematic Review Registration: https://www.crd.york.ac.uk/prospero/display_ record.php?ID=CRD42020200539; PROSPERO 2020, identifier: CRD42020200539.

Keywords: stroke, cortical thickness, cortical atrophy, recovery, brain lesion, diaschisis, plasticity, rehabilitation 


\section{INTRODUCTION}

Stroke is the leading cause of disability in western countries, with more than 3 million people left with a disability every year (Dobkin, 2005; Vos et al., 2016).

Stroke lesion triggers a multitude of systemic and cerebral effects, such as neurogenesis, gliogenesis and axonal sprouting, which, together with genetic (e.g., polymorphisms, transcriptome) and environmental factors (e.g., time point and intensity of rehabilitation), ultimately determine the long-term outcome and the degree of disability after rehabilitation (Cramer, 2008; Murphy and Corbett, 2009; Cramer et al., 2011; Di Pino et al., 2014, 2016; Di Lazzaro et al., 2015, 2016a; Bernhardt et al., 2017).

Direct contribution of lesion properties (e.g., side, location, etiology) to clinical outcome is limited and a significant role is played by alterations of brain areas beyond the lesion site (Dromerick and Reding, 1995; Pantano et al., 1996; Löuvbld et al., 1997; Miyai et al., 1997; Barber et al., 1998; Beaulieu et al., 1999; Chen et al., 2000; Vogt et al., 2012; Munsch et al., 2016; Dodd et al., 2017; Ernst et al., 2018; Pellegrino et al., 2019a). The latter mechanism is a solid concept in clinical and experimental neurology, introduced more than a century ago, and termed diaschisis (Carrera and Tononi, 2014).

The introduction of neuroimaging techniques allowing for whole brain functional mapping in vivo has demonstrated that behavioral impairments and potential recovery are linked to complex and distributed changes of brain functional activity and connectivity (Pellegrino et al., 2012, 2021; Silasi and Murphy, 2014; Burke Quinlan et al., 2015; Adhikari et al., 2017; Siegel et al., 2018). An overall rearrangement of brain function seems to occur in all stroke cases and is more pronounced in brain regions interconnected with the lesion site (Pellegrino et al., 2012; Di Lazzaro et al., 2014; Di Pino et al., 2014).

However, while a remarkable amount of research effort has been devoted to understanding changes of brain function, the effects of stroke on brain morphology, cortical thickness (CT) and cortical volume have not been fully characterized. It might be expected that regions beyond the lesion site may undergo cortical atrophy due to neuronal loss caused by disconnection (Carrera and Tononi, 2014; Di Pino et al., 2014). Conversely, brain regions may be expected to show cortical thickening of the areas participating during recovery via compensatory mechanisms, increased activity and consequently cortical plasticity (Di Pino et al., 2014). Alike functional changes, which show a dynamic evolution over time, potential changes of CT are expected to occur in a time period ranging from a few weeks to years after stroke lesion (Streitbürger et al., 2012).

The aim of this study is to systematically review the literature on the effects of stroke on CT beyond the lesion site and their potential relationship with clinical outcome in terms of sensorymotor function.

\section{METHODS}

The systematic review was conducted and reported according to the PRISMA guidelines (Moher et al., 2009), the protocol was registered on PROSPERO (https://www.crd.york.ac.uk/ prospero/), with registration number: CRD42020200539.

We searched PubMed, Scopus, Web of Science, Cochrane, Embase databases using the following keywords: "stroke," "cortical thickness," "cortical atrophy," "recovery," and "brain lesion," from inception until April the $16^{\text {th }}$ 2021. A detailed description of the search strategy can be found in Supplementary Materials (Appendix 1).

Articles were considered for inclusion only if:

(a) Enrolled subjects were stroke survivors, regardless of the nature and origin of the stroke (e.g., acute or chronic, ischaemic or haemorrhagic, cortical, subcortical, corticosubcortical).

(b) Human adults were enrolled ( $>18$ years of age).

(c) The relationship between CT and stroke functional recovery was explored, regardless of the experimental design.

Articles were excluded, if they enrolled animals or subjects affected from diseases other than stroke.

The literature search yielded a total of 821 results. After removing all duplicates, 662 articles were screened for inclusion by 2 independent review authors (AMC and LC), based on title and abstract, using the free online tool Rayyan (Ouzzani et al., 2016), for double blind selection. A third independent review author (AT) solved any disagreements. The full texts of the articles selected were independently reviewed by AMC and LC and the inclusion criteria were re-examined. Any disagreements were solved after discussion with a third reviewer (AT). Additionally, reference lists of the included articles were manually reviewed to increase the likelihood of identifying all relevant studies.

\section{Assessment of Risk of Bias in the Included Studies}

Methodological quality of original articles was assessed with the Newcastle-Ottawa Scale (NOS) for non-randomized studies (Stang, 2010) and the Cochrane risk of bias assessment tool for Randomized Controlled Trials (RCTs) (Cumpston et al., 2019). The NOS includes three domains: the selection item refers to the methods for participants' enrolment, the comparability domain indicates how well the analysis of confounding factors was managed and, finally, the exposure domain refers to the ascertainment of the exposure. For RCTs, assessment was conducted following the guidelines stated by the Cochrane Collaboration in their Cochrane Handbook for Systematic Reviews of Interventions (Cumpston et al., 2019). We evaluated the following bias domains: (1) Random sequence generation, (2) allocation concealment (3) blinding of participants and personnel (4) blinding of outcome assessment, (5) incomplete outcome data and (5) selective reporting.

\section{RESULTS}

Search strategy identified 821 records from five electronic databases, and 3 more studies were included from manual search of the reference lists of the previously retrieved articles. We 
furthermore added 2 papers that were found while conducting an initial search on PubMed. After removing 164 duplicates and 646 studies with unrelated target topics, 16 studies remained for full-text review.

After the screening of full texts, 4 papers were excluded from the qualitative analysis since they did not fully meet the inclusion criteria.

Finally, 12 studies were included for the qualitative analysis. Among them, 8 papers enrolled patients during the acute phase $(<5$ days post-stroke), whereas the remaining studies enrolled patients in the chronic phase (more than 6 months post stroke). The PRISMA flowchart of the review process is displayed in Figure 1. All relevant clinical, methodological and neuroimaging details are summarized in Table 1. We evaluated, if the retrieved data would be eligible for quantitative analysis (meta-analysis), which did not apply. The evaluation can be found in Appendix 2.

The cortical changes in regions different from the ischaemic lesioned area were the focus of the studies, together with investigating the related motor and sensory clinical outcomes. All the included studies found a variation of CT in brain areas beyond the stroke lesion both in the ipsilesional and contralesional hemisphere. Overall, the population included ischaemic stroke patients with lesions located prevalently in subcortical brain areas. As the included studies are rather heterogeneous, we report them below in two major groups: longitudinal studies and cross-sectional studies on patients with chronic stroke. The most relevant features and the methodology applied for each study are also reported in Table $\mathbf{1 .}$

\section{Longitudinal Studies}

\section{Bilateral Distant Changes in Cortical Thickness}

The study by Cai et al. (2016) longitudinally investigated the relationship between cortical volume extracted from MRI and clinical outcome measures, both administered in the acute phase (within 5 days) and at 1 year follow-up from stroke onset. The authors recruited 11 acute stroke patients with ischaemic subcortical stroke. Cortical volume was estimated from T1weighted images acquired on a 1.5 MR scanner. Voxel Based Morphometry (VBM) was performed with the VBM8 toolbox for SPM (https://www.fil.ion.ucl.ac.uk/spm/) to measure the potential changes in gray matter volume (GMV) after stroke, knowing that GMV contains information about CT and cortical surface area. The National Institutes of Health Stroke Scale (NIHSS) and Motricity Index (MI) were used as clinical outcome measures. Authors found a correlation between changes in GMV (corrected for lesion volume) and the clinical variables, specifically demonstrating that a more pronounced cortical atrophy in the precentral gyrus ipsilateral to stroke lesion correlated with a worse clinical recovery. Conversely, higher GMV of the contralateral orbitofrontal cortex (OFC) predicted a better motor recovery.

A recent work longitudinally investigated bilateral CT changes in basal ganglia stroke patients and healthy controls over a timespan of 6 months with 3 Tesla MRI (Liu et al., 2020). CT changes were assessed at five time points (within 7 days poststroke and again at 14,30,90, and 180 days after the event) in 33 patients. Patients were divided into 2 groups according to whether or not the lesions affected the functional motor regions of the striatum, defined using resting state f-MRI (the striatal motor group - SMD and the non-striatal motor group - N-SMD). Patients' motor function was assessed by the FuglMeyer scale performed before and after each MRI scan. Structural MRI data were processed using Freesurfer. Fourteen patients were classified into the SMD and 19 into the N-SMD. The cortical thickness changes were explored comparing the baseline and 180 days post stroke images across all stroke participants and a significant increase in cortical thickness was found both in the ipsilesional (frontal pole, superior frontal gyrus, medial prefrontal cortex) and contralesional hemisphere (frontal pole, precentral gyrus, ventrolateral prefrontal cortex, superior frontal gyrus, medial prefrontal cortex, superior and middle temporal gyri). Furthermore, the evolution of these changes throughout the five time points was explored and a significant increase in CT over time was seen in the ipsilateral and contralateral hemisphere in the patient group; in comparison, healthy control participants demonstrated no cortical thickness changes over time or at any point. Moreover, the SMD and N-SMD groups underwent different patterns of cortical reorganization after stroke. The CT differences between 7 and 180 days post-stroke did not correlate with improvement in Fugl-Meyer scores suggesting that CT changes may not have a linear relationship with motor improvement. Instead, the SMD group exhibited a larger motor impairment compared to the N-SMD group, which underlines the importance of considering the stroke location when assessing symptoms and recovery. These study findings showed that CT changes appear over time and in cortical areas beyond the lesion site and that these changes are due to post stroke reorganization, given the fact that healthy controls did not show increase in CT. This increase in CT might be a product of motor recovery and motor compensation even if no correlation with motor score was found.

Cheng et al. (2020) reported another longitudinal study with a follow up of 1 year, conducted on 18 patients with subcortical ischaemic stroke and upper limb paresis. In this study the authors' aim was to test, if selective cortical atrophy of brain areas connected to subcortical stroke lesions was observable in the late chronic stage after stroke specifically in the contralesional homologous brain areas. T1-weighted and DTI images were acquired on a 3T MRI scanner and only NIHSS, FMA and grip strength were considered as clinical outcome measures. Clinical and imaging data were collected at 3-5 days after stroke and after 1 year. CT was measured using the Freesurfer software from T1weighted images. Results showed that cortical atrophy involved regions connected with the lesion on both the affected and unaffected hemispheres. At the 1 year follow up no relationship between CT and clinical outcome was found.

The hypothesis that after a subcortical stroke there is a secondary decay of CT in the motor areas related to the degree of motor function impairment was longitudinally investigated in another study by Liu et al. (2015). With their work, they aimed at confirming that, after an initial reduction of CT, there is a progressive increase in the neuronal activity in motor areas, which might be correlated with motor function recovery after stroke. To confirm this hypothesis CT analysis from structural 


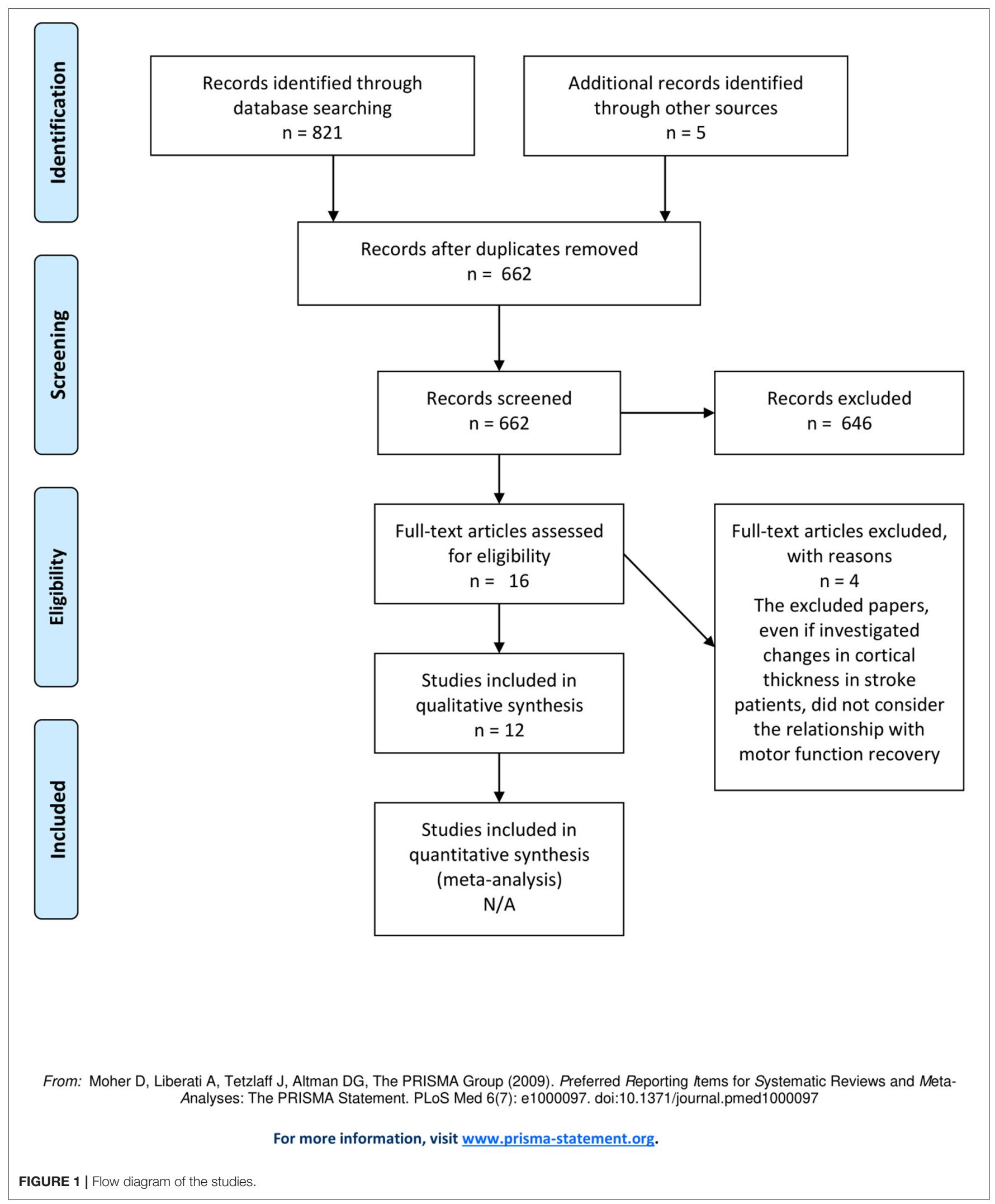




\begin{tabular}{|c|c|c|c|c|c|c|c|}
\hline & Aim & Type of study & Methods & $\begin{array}{l}\text { Participant } \\
\text { characteristics }\end{array}$ & Clinical measures & Imaging measures & Findings \\
\hline $\begin{array}{l}\text { Buetefisch et al. } \\
\text { (2018) } \\
\text { Journal of } \\
\text { Neurophisiology }\end{array}$ & $\begin{array}{l}\text { To evaluate, if the affected } \\
\text { hand function in chronic } \\
\text { stroke is related to } \\
\text { structural and functional } \\
\text { reorganization of M1 and } \\
\text { CST of the lesioned } \\
\text { hemisphere. }\end{array}$ & Case-control & $\begin{array}{l}\text { CT and FA served } \\
\text { as measures of M1 } \\
\text { and CST structure. } \\
\text { Images were } \\
\text { obtained on a } \\
\text { Siemens 3T Trio } \\
\text { scanner using a } \\
\text { 12-channel } \\
\text { head coil. }\end{array}$ & $\begin{array}{l}18 \text { patients with chronic } \\
\text { stroke involving either M1 } \\
\text { and/or the CST. Cortical } \\
\text { and subcortical stroke. } \\
\text { Stroke data were } \\
\text { compared with data from } \\
18 \text { age-matched healthy } \\
\text { subjects. }\end{array}$ & $\begin{array}{l}\text { MRC; modified } \\
\text { Ashworth scale; JTT; } \\
\text { peak acceleration of } \\
\text { wrist extension } \\
\text { movements for affected } \\
\text { hand function; WMFT; } \\
\text { MAL. }\end{array}$ & $\begin{array}{l}\mathrm{CT} \text { and FA as a measure } \\
\text { of } \mathrm{M} 1 \text { and } \mathrm{CST} \text {, } \\
\text { respectively. } \\
\text { CT measured using the } \\
\text { Freesurfer software. }\end{array}$ & $\begin{array}{l}\text { In chronic stroke patients } \\
\text { with injury to M1 and/or } \\
\text { CST an abnormally reduced } \\
\text { M1 output is not related to } \\
\text { impaired hand function. }\end{array}$ \\
\hline $\begin{array}{l}\text { Cai et al. (2016) } \\
\text { Frontiers in Human } \\
\text { Neuroscience }\end{array}$ & $\begin{array}{l}\text { To investigate the potential } \\
\text { structural cortical } \\
\text { reorganization after } \\
\text { subcortical stroke } \\
\text { comparing findings on the } \\
\text { acute phase (within } 5 \\
\text { days from the stroke) and } \\
\text { at } 1 \text { year. }\end{array}$ & Longitudinal study & $\begin{array}{l}\text { 1.5T MR scanner, } \\
\text { T1W images. }\end{array}$ & $\begin{array}{l}11 \text { right-handed patients } \\
\text { with acute subcortical } \\
\text { ischemic infarctions } \\
\text { involving the basal ganglia } \\
\text { regions. }\end{array}$ & NIHSS; MI & $\begin{array}{l}\text { Gray matter volume } \\
\text { obtained with VBM } \\
\text { analyzed using a VBM8 } \\
\text { toolbox implemented in } \\
\text { the SPM software. }\end{array}$ & $\begin{array}{l}\text { Structural reorganization of } \\
\text { the contralesional } \\
\text { cognitive-related cortices } \\
\text { might contribute to motor } \\
\text { recovery after subcortical } \\
\text { stroke. }\end{array}$ \\
\hline $\begin{array}{l}\text { Chen et al. (2019) } \\
\text { European radiology }\end{array}$ & $\begin{array}{l}\text { To identify regions causally } \\
\text { influenced by thalamic } \\
\text { stroke and to determine } \\
\text { the association between } \\
\text { structural/functional } \\
\text { alteration and } \\
\text { somatosensory } \\
\text { dysfunction. }\end{array}$ & $\begin{array}{l}\text { Case-control } \\
\text { study }\end{array}$ & $\begin{array}{l}\text { 3T MRI scanner. } \\
\text { T1W; DTI; rsfMRI. }\end{array}$ & $\begin{array}{l}31 \text { participants with } \\
\text { chronic thalamic infarct } \\
\text { and somatosensory } \\
\text { dysfunction vs. } 32 \text { healthy } \\
\text { controls. }\end{array}$ & NIHSS; FMA; BI; LMA & $\begin{array}{l}\text { DTI; } \\
\text { FA; } \\
\text { rsFC. } \\
\text { Cortical volume was } \\
\text { calculated with the } \\
\text { Freesurfer software. }\end{array}$ & $\begin{array}{l}\text { Thalamic infarcts induce } \\
\text { remote changes in the } \mathrm{S} 1 \\
\text { and this network of } \\
\text { abnormality underlies the } \\
\text { cause of the sensory } \\
\text { deficits. }\end{array}$ \\
\hline $\begin{array}{l}\text { Cheng et al. (2015) } \\
\text { Journal of cerebral } \\
\text { blood flow and } \\
\text { metabolism. }\end{array}$ & $\begin{array}{l}\text { To elucidate the impact of } \\
\text { focal subcortical stroke } \\
\text { lesions on CT. }\end{array}$ & $\begin{array}{l}\text { Prospective MRI } \\
\text { study with } \\
\text { assessment at the } \\
\text { acute phase and } \\
\text { 3-month follow-up }\end{array}$ & $\begin{array}{l}\text { 3T MRI scanner. } \\
\text { T1W and DTI } \\
\text { images acquired. }\end{array}$ & $\begin{array}{l}12 \text { patients with upper } \\
\text { extremity paresis resulting } \\
\text { from acute ischaemic } \\
\text { subcortical stroke. }\end{array}$ & $\begin{array}{l}\text { NIHSS; mRS; UEFM; } \\
\text { ARAT; grip force }\end{array}$ & $\begin{array}{l}\text { Combined white-matter } \\
\text { tractography and } \\
\text { semi-automatic } \\
\text { measurement of CT } \\
\text { using the Freesurfer } \\
\text { software. }\end{array}$ & $\begin{array}{l}\text { There is a specific impact of } \\
\text { subcortical lesions on } \\
\text { distant, yet connected } \\
\text { cortical areas. }\end{array}$ \\
\hline $\begin{array}{l}\text { Cheng et al. (2020) } \\
\text { Journal of cerebral } \\
\text { blood flow and } \\
\text { metabolism }\end{array}$ & $\begin{array}{l}\text { To test if selective cortical } \\
\text { atrophy of brain areas } \\
\text { connected to subcortical } \\
\text { stroke lesions is } \\
\text { observable in the late } \\
\text { chronic stage } 1 \text { year after } \\
\text { stroke, specifically in } \\
\text { contralesional, } \\
\text { homologous brain areas. }\end{array}$ & $\begin{array}{l}\text { Prospective MRI } \\
\text { study with } \\
\text { assessment at the } \\
\text { acute phase and } 1 \\
\text { year follow-up }\end{array}$ & $\begin{array}{l}\text { 3T MRI scanner. } \\
\text { T1W and DTI } \\
\text { images acquired. }\end{array}$ & $\begin{array}{l}18 \text { patients with chronic } \\
\text { subcortical stroke. }\end{array}$ & NIHSS; UEFM; mRS & $\begin{array}{l}\text { Combined white-matter } \\
\text { tractography and } \\
\text { semi-automatic } \\
\text { measurement of CT } \\
\text { using the Freesurfer } \\
\text { software. }\end{array}$ & $\begin{array}{l}\text { Atrophy of remote cortical } \\
\text { areas connected to single } \\
\text { subcortical lesions remain } \\
\text { prominent one year after } \\
\text { ischemic stroke. } \\
\text { Contralesional cortical } \\
\text { atrophy is detectable in } \\
\text { homologous cortical areas. }\end{array}$ \\
\hline
\end{tabular}




\begin{tabular}{|c|c|c|c|c|c|c|c|}
\hline & Aim & Type of study & Methods & $\begin{array}{l}\text { Participant } \\
\text { characteristics }\end{array}$ & Clinical measures & Imaging measures & Findings \\
\hline $\begin{array}{l}\text { Gauthier et al. (2012) } \\
\text { Stroke }\end{array}$ & $\begin{array}{l}\text { 1. to evaluate the } \\
\text { relationship between } \\
\text { chronic motor deficits in } \\
\text { stroke and the degree of } \\
\text { thinning in } \\
\text { normal-appearing brain } \\
\text { regions on MRI. } 2 \text {. to see } \\
\text { if regional gray matter } \\
\text { thinning in chronic stroke } \\
\text { patients before treatment } \\
\text { is related to the magnitude } \\
\text { of improvement in motor } \\
\text { status after CIMT. }\end{array}$ & $\mathrm{RCT}$ & $\begin{array}{l}\text { 1.5T MRI or 3T } \\
\text { MRI scanner. T1W } \\
\text { MRI VBM to relate } \\
\text { gray matter density } \\
\text { (in brain areas } \\
\text { without visible } \\
\text { damage) to motor } \\
\text { status of the } \\
\text { paretic arm. }\end{array}$ & $\begin{array}{l}85 \text { chronic stroke patients } \\
\text { with mild-moderate motor } \\
\text { deficit. }\end{array}$ & MAL; WMFT & $\begin{array}{l}\text { Gray matter density with } \\
\text { Voxel Based } \\
\text { Morphometry (VBM) } \\
\text { using SPM5 toolbox, }\end{array}$ & $\begin{array}{l}\text { Pre-treatment: lower MAL } \\
\text { and longer performances at } \\
\text { WMFT correlated with } \\
\text { reduced GM density in ipsi- } \\
\text { and contralateral } \\
\text { motor areas. Less } \\
\text { improvement of WMFT and } \\
\text { MAL following CIMT was } \\
\text { predicted by reduced GM } \\
\text { density in motor areas } \\
\text { remote from the infarct. }\end{array}$ \\
\hline $\begin{array}{l}\text { Jones et al. (2016) } \\
\text { Restor Neurol } \\
\text { neurosc }\end{array}$ & $\begin{array}{l}\text { To see how regional } \\
\text { structural differences, } \\
\text { including CT, may be } \\
\text { associated with metabolic } \\
\text { function after stroke. }\end{array}$ & $\begin{array}{l}\text { Cross-sectional } \\
\text { study }\end{array}$ & $\begin{array}{l}\text { 3T MRI scanner. } \\
\text { Metabolic and } \\
\text { structural (T1W } \\
\text { MRI) assessment of } \\
\text { the primary motor } \\
\text { cortex using H1 } \\
\text { magnetic } \\
\text { resonance } \\
\text { spectroscopy and } \\
\text { CT measurement. } \\
\text { Average CT in the } \\
\text { precentral gyrus in } \\
\text { both stroke } \\
\text { (ipsilesional/contralesion } \\
\text { and control (non- } \\
\text { dominant/dominant) } \\
\text { groups } \\
\text { was compared. }\end{array}$ & $\begin{array}{l}17 \text { subcortical ischaemic } \\
\text { stroke in the chronic } \\
\text { phase (>6 months) and } \\
11 \text { neurologically healthy } \\
\text { controls } \\
\text { nal) }\end{array}$ & WMFT & $\begin{array}{l}\text { INAA concenration } \\
\text { Glx concentration } \\
\text { precentral gyrus } \\
\text { thickness CT measured } \\
\text { with surface based } \\
\text { cortical morphometry } \\
\text { using Freesurfer. }\end{array}$ & $\begin{array}{l}\text { Ipsilesional precentral gyrus } \\
\text { thickness and tNAA } \\
\text { concentration were } \\
\text { associated with UE } \\
\text { motor performance. } \\
\text { Precentral gyrus thickness } \\
\text { was significantly lower in the } \\
\text { stroke group compared to } \\
\text { the control group, and } \\
\text { ipsilesional thickness in the } \\
\text { stroke group was not } \\
\text { significantly associated with } \\
\text { UE motor performance. }\end{array}$ \\
\hline $\begin{array}{l}\text { Kraemer et al. (2004) } \\
\text { The American } \\
\text { society of } \\
\text { neuroimaging }\end{array}$ & $\begin{array}{l}\text { To assess post-ischemic } \\
\text { brain. }\end{array}$ & $\begin{array}{l}\text { Retrospective } \\
\text { study }\end{array}$ & 1.5T MRI. T1W MRI & $\begin{array}{l}10 \text { patients suffering from } \\
\text { a first acute cerebral } \\
\text { ischemia in the territory of } \\
\text { the middle cerebral artery. }\end{array}$ & ESS & T1W MRI, VGM & $\begin{array}{l}\text { Delayed brain atrophy after } \\
\text { acute ischemic stroke } \\
\text { involved areas anatomically } \\
\text { connected with the } \\
\text { ischemic brain lesion, that } \\
\text { was accompanied by a } \\
\text { simultaneous improvement } \\
\text { of the neurological deficit. }\end{array}$ \\
\hline $\begin{array}{l}\text { Liu et al. (2015) } \\
\text { European journal of } \\
\text { neurology }\end{array}$ & $\begin{array}{l}\text { To assess the relationship } \\
\text { between the spontaneous } \\
\text { neuronal activity in the } \\
\text { motor-related cortex and } \\
\text { motor recovery. }\end{array}$ & $\begin{array}{l}\text { Case-control } \\
\text { study }\end{array}$ & 3T MRI. T1W & $\begin{array}{l}22 \text { patients with acute } \\
\text { subcortical infarct and } 22 \\
\text { healthy subjects }\end{array}$ & FMA; NIHSS & $\begin{array}{l}\text { CT analysis combined } \\
\text { with ALFF calculation; } \\
\text { FMA. }\end{array}$ & $\begin{array}{l}\text { Increased spontaneous } \\
\text { neuronal activity of M1 area } \\
\text { may contribute to early } \\
\text { motor recovery in patients } \\
\text { with subcortical infarction. }\end{array}$ \\
\hline
\end{tabular}


TABLE 1 | Continued

\begin{tabular}{|c|c|c|c|c|c|c|c|}
\hline & Aim & Type of study & Methods & $\begin{array}{l}\text { Participant } \\
\text { characteristics }\end{array}$ & Clinical measures & Imaging measures & Findings \\
\hline $\begin{array}{l}\text { Liu et al. (2020) } \\
\text { Neurology }\end{array}$ & $\begin{array}{l}\text { Cortical thickness was } \\
\text { measured over a } 6 \\
\text { months period to } \\
\text { investigate cortical } \\
\text { reorganization after basal } \\
\text { ganglia stroke. }\end{array}$ & $\begin{array}{l}\text { Case-control } \\
\text { study }\end{array}$ & $\begin{array}{l}\text { 3T MRI at } 1-7,14 \text {, } \\
\text { 30, } 90,180 \text { days } \\
\text { post-stroke (T1-T2 } \\
\text { and FLAIR) }\end{array}$ & $\begin{array}{l}33 \text { patients with first } \\
\text { episode basal ganglia } \\
\text { stroke and } 23 \\
\text { age-matched control } \\
\text { participants }\end{array}$ & FMA & $\begin{array}{l}\text { CT measured with the } \\
\text { Freesurfer software. }\end{array}$ & $\begin{array}{l}\text { Increased CT in the } \\
\text { ipsilateral and contralateral } \\
\text { hemisphere were seen in } \\
\text { patient's group at six } \\
\text { months post stroke. CT } \\
\text { increase was uncorrelated } \\
\text { with behavioral } \\
\text { improvement or with the } \\
\text { FMA at the baseline. }\end{array}$ \\
\hline $\begin{array}{l}\text { Sterr et al. (2013) } \\
\text { Neuroimage: Clinical }\end{array}$ & $\begin{array}{l}\text { To examine structural } \\
\text { changes in the } \\
\text { non-lesioned hemisphere } \\
\text { of } 31 \text { patients with chronic } \\
\text { stroke undergoing CIMT. It } \\
\text { was assumed that CT } \\
\text { would change with the } \\
\text { intervention and that this } \\
\text { change should be greater } \\
\text { in CIMT. }\end{array}$ & $\mathrm{RCT}$ & $\begin{array}{l}\text { 3T MRI. } \\
\text { T1-weighted; DWI }\end{array}$ & $\begin{array}{l}31 \text { patients with moderate } \\
\text { to severe chronic } \\
\text { upper-limb hemiparesis of } \\
\text { the left }(N=15) \text { or the } \\
\text { right }(N=16) \text { arm } \\
\text { following first ever stroke } \\
\text { (14 CIMT, } 17 \text { NO CIMT) }\end{array}$ & MAL; WMFT & $\begin{array}{l}\text { CT measured with the } \\
\text { Freesurfer software. }\end{array}$ & $\begin{array}{l}\text { Non-lesioned hemisphere } \\
\text { analysis revealed an } \\
\text { increase in CT after therapy } \\
\text { with a cluster peak centered } \\
\text { over the precentral gyrus, } \\
\text { postcentral gyrus There was } \\
\text { no correlation between } \\
\text { treatment effect and FA in } \\
\text { the } \\
\text { non-lesioned hemisphere } \\
\mathrm{CT} \text { in the contralesional } \\
\text { hemisphere is not altered } \\
\text { by CIMT. }\end{array}$ \\
\hline $\begin{array}{l}\text { Yu et al. (2017) } \\
\text { European Journal of } \\
\text { Neuroscience }\end{array}$ & $\begin{array}{l}\text { Gray matter atrophy } \\
\text { co-existed with brain } \\
\text { plasticity presenting with } \\
\text { structural remolding and } \\
\text { hyperperfusion in specific } \\
\text { GM regions during stroke } \\
\text { recovery. }\end{array}$ & Prospective & $\begin{array}{l}\text { MRI scans on a } 3 T \\
\text { scanner in the } \\
\text { acute phase and } 6 \\
\text { month follow-up. } \\
\text { MRI to detect the } \\
\text { GM volume change } \\
\text { and non-invasive } \\
\text { ASL-MRI to } \\
\text { quantify } \\
\text { CBF change. }\end{array}$ & $\begin{array}{l}12 \text { acute ischaemic stroke } \\
\text { patients with pure } \\
\text { subcortical lesions. }\end{array}$ & NIHSS; BI & GMV using SPM8, CBF & $\begin{array}{l}\text { Decreased GMV: ipsilateral } \\
\text { post-central gyrus, } \\
\text { pre-central gyrus, } \\
\text { precuneus, angular gyrus, } \\
\text { insula, thalamus and } \\
\text { cerebellum. Increased GMV: } \\
\text { ipsilesional hippocampus, } \\
\text { contralesional orbital gyrus } \\
\text { and lingual gyrus. } \\
\text { Decreased GMV in the } \\
\text { anterior lobe of cerebellum } \\
\text { was negatively associated } \\
\text { with improvement of Bl. }\end{array}$ \\
\hline
\end{tabular}

M1, primary motor cortex; CST, cortico-spinal tract; CT, cortical thickness; FA, Fractional Anisotropy; MRC, Medical Research Council; JTT, Jebsen-Taylor Test; WMFT, Wolf Motor Function Test; MAL, Motor Activity Log; VBM, Voxel Based Morphometry; NIHSS, National Institutes of Health Stroke Scale; MI, Motricity Index; FMA, Fugl Meyer Assessment; BI, Barthel Index; LMA, Lindmark assessment; DTI, diffusion tensor imaging; rsFC, resting state functional connectivity; S1:somatosensory area; mRS, modified Rankin Scale; UEFM upper extremity Fugl-Mayer; ARAT, Action Research Arm Test; CIMT, Constraint induced movement therapy; SPM, Statistical Parametric Mapping; GM, gray matter; tNNA, total N-acetylaspartate; Glx, glutamate+glutamine; ESS, European Stroke Scale; ALFF, amplitude of low frequency fluctuation; VGM, voxel guided morphometry; ALS-MRI Arterial Spin Labeling MRl; CBF, cerebral blood flow. 
T1 MRI and a functional parameter from resting state MRI were combined. 3T MRIs were performed in the acute phase (before day 7 post stroke), after 4 weeks and after 12 weeks. The population included 22 patients with acute ischaemic subcortical stroke and 22 healthy controls. The authors assessed patients' motor function with FMA and NIHSS before each MRI examination and the correlation between motor outcome and changes in the investigated imaging indices was additionally explored. Authors found that CT was reduced in the premotor cortex, supplementary motor cortex (SMC) and precuneus 12 weeks after stroke. Interestingly, an increase was found in mean CT in the supplementary motor cortex and the insula of the unaffected hemisphere. The thickening of the contralesional SMC was correlated with changes in FMA scores and patients with significantly increased CT in the contralesional SMC experienced a greater improvement in motor function.

Furthermore, Kraemer et al. (2004) aimed at assessing the relationships between cortical volume in the acute and chronic phases after ischemic brain lesion and clinical recovery. Their study retrospectively included 10 patients affected from ischaemic stroke in the territory of the middle cerebral artery assessed with the European Stroke Scale (ESS), which was administered in combination with their MRIs. T1-weighted images were acquired on a $1.5 \mathrm{~T}$ MRI scanner at acute and chronic stage, but time of acquisitions were not standardized, thus it should be considered as limitation. To assess cortical brain volumes they used MRI voxel-guided morphometry. Results revealed a shrinkage in cortical volume in brain areas exceeding the ischaemic lesion. Remote changes were found in the ipsilateral hemisphere and, in several patients, in the contralateral one. Brain volume alterations were not related to age, recovery or time between scans. The authors hypothesized that paresis and reduced usage may lead to secondary changes in cortical brain volume.

The post-stroke recovery variability issue drove the group by $\mathrm{Yu}$ et al. (2017) to investigate the differences in the gray matter volume and cerebral blood flow in acute vs. chronic subcortical stroke in depth. The background hypothesis was that comparing brain reorganization at different times from onset could provide insights into the functional and anatomical bases of recovery after stroke. In the study design the time interval between scans was variable (ranging from 3 to 8 months) and imaging results were correlated with BI and NIHSS as outcome measures. Data from 12 acute stroke patients were analyzed, high resolution T1-weighted MRIs were acquired on a 3T scanner and data were processed with the voxel-based morphometry 8 (VBM 8) toolbox for Statistical Parametric Mapping 8 (SPM8). Cortical volume was significantly reduced from acute to chronic phase in several regions of the ipsilesional hemisphere such as the post central gyrus, the precentral gyrus, the insula, the precuneus, the angular gyrus, the thalamus, and the anterior cerebellar lobe. Also, cortical thinning was found in the anterior and posterior cerebellar lobes. Cortical thickening was seen in the ipsilesional hippocampus and the contralesional orbital and the lingual gyrus. Only the anterior cerebellar lobe atrophy in the contralesional hemisphere was negatively correlated with recovery. Interestingly, atrophy in the precentral gyrus, the main area of voluntary movements, had no effects on stroke recovery. Based on these findings, the authors hypothesized that the increased volume in specific brain regions may be a compensatory response in promoting recovery after stroke.

\section{Ipsilateral Distant Changes in Cortical Thickness}

Cheng et al. (2015) conducted a prospective study investigating the impact of subcortical stroke lesions on CT and on the recovery of upper limb function. Twelve acute ischaemic stroke patients with subcortical brain infarct were recruited and underwent a 3-month follow-up. The outcome of interest for functional recovery was the upper limb function, assessed by NIHSS, Action Research Arm Test (ARAT), Fugl-Mayer (FMA) and grip strength. Imaging data consisted of T1-weighted and DTI images acquired on a $3 \mathrm{~T}$ MRI scanner combined with clinical examination (i.e., 3-5 days and 3 months after stroke). The study looked at CT changes between regions connected to the lesioned stroke area both in the affected and the unaffected hemisphere. Imaging data analysis was performed using the Freesurfer software package (Dale et al., 1999) (https:// surfer.nmr.mgh.harvard.edu/). Clinical outcome measures of motor function improved in all patients. Results from cortical measurements showed significant cortical thinning involving the superior frontal gyrus and regions at the border of the supplementary motor area in the affected hemisphere, while nonsignificant changes were found in the unaffected hemisphere. The lesion size did not correlate with the CT changes. No direct effect of such thinning on upper limb motor performance was found and relative changes of clinical outcome measures were not significantly correlated with changes in CT. The authors speculated that the lack of correlation between CT changes and functional recovery could be due to the short follow-up period and the small sample size.

\section{Cross-Sectional and Chronic Stroke Studies Bilateral or Contralesional Distant Changes in Cortical Thickness}

Gauthier et al. (2012), aimed at evaluating the relationships between chronic motor deficit of the upper limb in stroke patients and the amount of thinning in brain regions not apparently affected. In addition, the study aimed at addressing the question of whether regional gray matter thinning can be related to the improvement of upper limb function after Constraint Induced Movement Therapy (CIMT). To answer the research question, they recruited 85 chronic stroke patients and assessed their upper limb function with the MAL and WMFT. Forty-four subjects underwent MRI scans and T1-weighted MR images were acquired on a $1.5 \mathrm{~T}$ or a $3 \mathrm{~T}$ scanner; cortical features were measured with voxel-based morphometry (VBM). The authors investigated the relationships between gray matter density and upper limb recovery to calculate a pre-treatment motor status and subsequently looked at the same measures in the CIMT group. The authors found that better clinical outcome, and in this case also clinical benefit after CIMT, was related to cortical thickness of the sensory-motor regions of the healthy hemisphere. 
The relationship between CIMT and cortical morphology was also investigated by Sterr et al. (2013). The authors looked at CT variations in 31 patients with moderate to severe chronic stroke sequelae and compared CIMT vs. standard therapy. A 3T MRI scanner was used to acquire T1-weighted MR images that were processed for surface based analysis with Freesurfer. To assess motor function, the MAL and WMFT were administered before and after therapy. Results showed a significant improvement in all the clinical measures in the CIMT when compared with the control group. CT changed in the precentral and the post central gyrus of the non-lesioned hemisphere, no difference between groups was found. Furthermore, no significant cortical changes associated with modification in clinical outcomes were seen. The authors speculated that the variation of cortical properties reflected the use-dependent structural changes, such as the increase in synapses, dendrites, axonal spines and glial cells.

\section{Ipsilateral Distant Changes in Cortical Thickness}

Focusing on chronic patients, Buetefisch et al. (2018) aimed at evaluating, if impairment of hand function is related to structural and functional reorganization of the primary motor cortex (M1) and its corticospinal projections of the lesioned hemisphere. Eighteen patients with cortical and subcortical ischaemic infarction involving the primary motor area and the corticospinal tract (CST) were studied. Hand motor function was assessed with the Jebsen-Taylor test and a kinematic measure of hand function, i.e., the peak acceleration of wrist extension movements. Furthermore, the Wolf Motor Function Test (WMFT) and the Motor Activity Log (MAL) were used. Data from patients were compared with data from two groups of age-matched healthy subjects. It was found that the primary motor cortex of the affected hemisphere was thinner than the contralateral. A significant association between hand function and structural integrity of the primary motor system, as measured by the primary motor cortex thickness and cortical anisotropy of the cortico-spinal tract, was not found. A limitation of this study is that it was not possible to distinguish if the process leading to the changes in M1 CT is regenerative or degenerative since they didn't have a second set of measurements for comparison.

A definite focus on the neural substrate underpinning upper limb recovery after stroke was the aim of Jones et al. (2016) who used biochemical and MRI approaches within the framework of a case control study design. A total of 17 patients with chronic subcortical stroke and 11 healthy controls were recruited. The authors wanted to quantify anatomical and metabolic differences in the primary motor cortex and to look at their relationships with the hemiparetic arm function recovery in chronic stroke patients. Participants underwent 3T MRI scans and functional assessment. Cortical reconstruction and segmentation were performed with the Freesurfer software. Total N-acetylaspartate (t-NAA) and glutamate (Glx) concentrations were measured, as both are altered in chronic stroke and their level of change is related to arm impairment and CT (Cirstea et al., 2011, 2012). Upper limb motor function was assessed with the WMFT. A significant positive correlation was found between tNAA and M1 thickness for ipsilesional and contralesional hemispheres in the stroke group, and tNAA concentration explained a larger amount of variance in motor performance. The precentral gyrus thickness was significantly lower in the stroke group where ipsilesional thickness was not significantly associated with motor performance.

Finally, Chen et al. (2019) highlighted the somatosensory deficits in thalamic stroke with the aim to identify cortical regions causally influenced by the ischaemic damage and to determine the association between structural/functional alteration and somatosensory impairment. To fulfill this purpose, 31 patients with chronic sensory-motor impairments secondary to thalamic infarction and 32 age and sex-matched healthy controls were enrolled. Clinical examination included NIHSS, FMA, Barthel Index and Lindmark assessment. MRIs were acquired with a $3 \mathrm{~T}$ scanner and cortical measures were extracted from the T1-weighted images employing Freesurfer. Results revealed decreased cortical volume in the ipsilesional primary somatosensory cortex demonstrating a link between alteration of the cortical volume and somatosensory impairment.

\section{Risk of Bias in Included Studies}

The methodological quality of the 10 non-randomized controlled studies was assessed by the Newcastle-Ottawa Scale and all studies received a NOS score $<9$, indicating a low methodological quality. The Risk of Bias Cochrane tool was used for methodological assessment of the 2 Randomized Controlled Trials and highlighted lack of information regarding randomization, allocation procedures and blinding of outcome assessment in all the studies. The detailed methodological assessment of non-RCTs is presented in Table 2, whereas the methodological assessment of RCTs is shown in Figure 2.

\section{Excluded Studies}

Four studies were excluded after reading the full text since they did not investigate the relation between sensory-motor recovery and CT (Brodtmann et al., 2012; Zhang et al., 2014;

TABLE 2 | Methodological quality of the included studies according to the Newcastle-Ottawa Scale (NOS) for case-control studies.

\begin{tabular}{|c|c|c|c|c|}
\hline References & Selection & Comparability & Exposure & NOS score \\
\hline $\begin{array}{l}\text { Buetefisch et al. } \\
\text { (2018) }\end{array}$ & 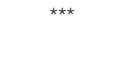 & $\star \star *$ & 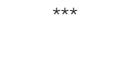 & 8 \\
\hline Cai et al. (2016) & 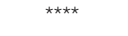 & * & 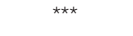 & 8 \\
\hline Chen et al. (2019) & 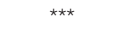 & $\star \star *$ & 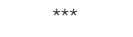 & 8 \\
\hline Cheng et al. (2015) & 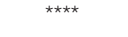 & & 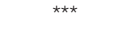 & 7 \\
\hline Cheng et al. (2020) & 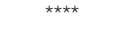 & & $\star \star \star ~$ & 7 \\
\hline Jones et al. (2016) & $\star \star \star *$ & & $\star * \star$ & 6 \\
\hline $\begin{array}{l}\text { Kraemer et al. } \\
\text { (2004) }\end{array}$ & $\star \star$ & & 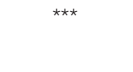 & 5 \\
\hline Liu et al. (2015) & $\star \star \star *$ & $\star \star$ & * & 6 \\
\hline Liu et al. (2020) & 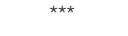 & & $\star \star$ & 5 \\
\hline Yu et al. (2017) & 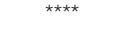 & & $\star \star \star$ & 7 \\
\hline
\end{tabular}

This table identifies "high" quality choices with a "star." A study can be awarded a maximum of four stars ${ }^{\left.{ }^{* \star *}\right)}$ within the Selection category and a maximum of three stars $\left.{ }^{(\star \star}\right)$ within the Exposure category. A maximum of two stars $\left.{ }^{(* \star}\right)$ can be given for Comparability. Studies can be divided into very high group quality (NOS score $=9$ ) and lower quality group (score <9) for analysis. 


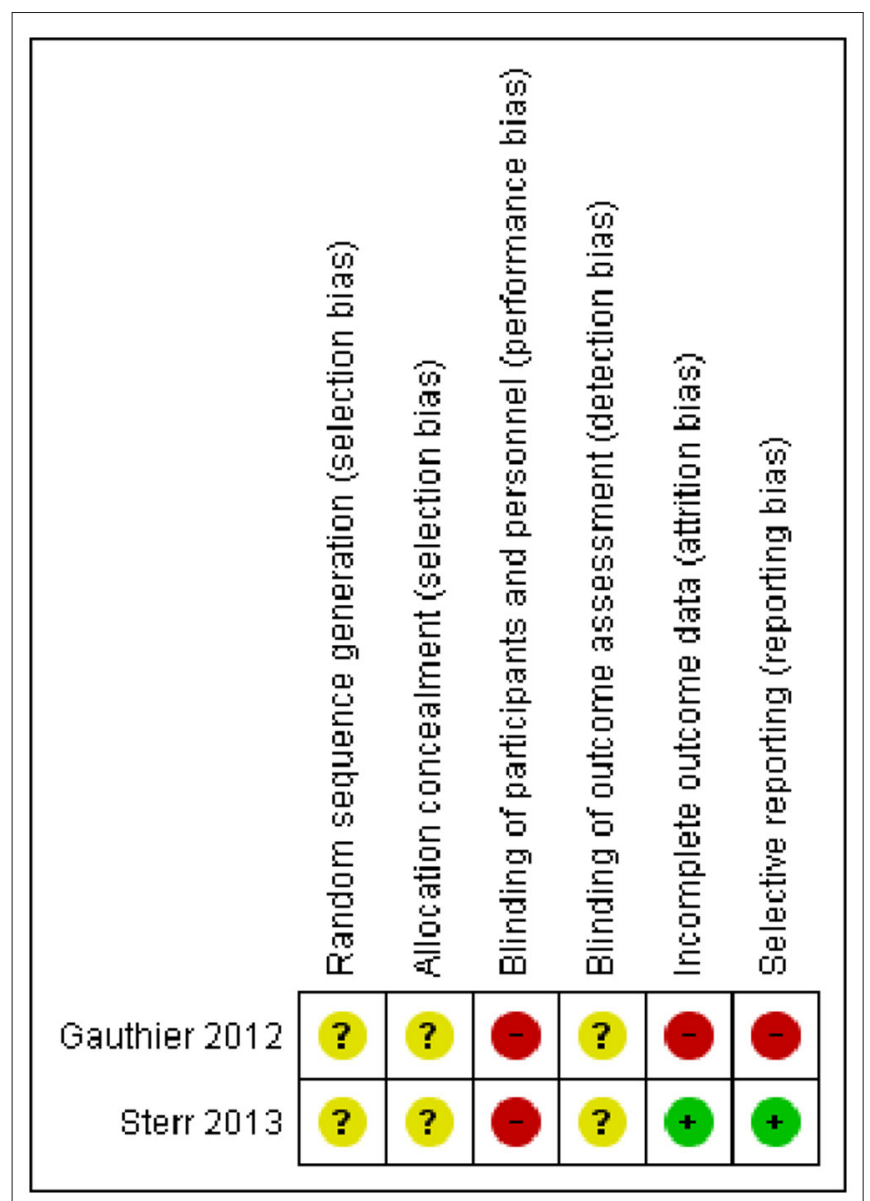

FIGURE 2 | Risk of bias summary for Randomized Controlled Trials. Depicted are the review authors' judgements about each risk of bias item for the two included randomized controlled trials.

Duering et al., 2015; Werden et al., 2017). A detailed description of excluded studies is reported in the Appendix 3 of the Supplementary Materials.

\section{DISCUSSION}

In this review we aimed at identifying the effects of post-stroke changes in cortical thickness beyond the primary lesion location on sensory-motor outcomes. Twelve studies were included of which eight were focusing on subcortical lesions exclusively and four included patients with cortical and subcortical lesions. While seven studies could not show an association between $\mathrm{CT}$ and sensory-motor outcomes the remaining five found this correlation. Ten studies were case-control studies (Kraemer et al., 2004; Cheng et al., 2015, 2020; Liu et al., 2015, 2020; Cai et al., 2016; Jones et al., 2016; Yu et al., 2017; Buetefisch et al., 2018; Chen et al., 2019), while two were randomized controlled trials (Gauthier et al., 2012; Sterr et al., 2013).

Specifically, three studies show that a thinning of the ipsilesional pre- or postcentral gyrus was associated with worse motor and somatosensory recovery, respectively (Gauthier et al.,
2012; Cai et al., 2016; Chen et al., 2019). This result was reproduced in a longitudinal design, a case control design and a cross-sectional design. This implies that (a) there might be a reduction in sensory-motor cortex volume in stroke secondary to primary lesion as a factor of time, (b) there might be a difference between cortical volume in stroke patients as compared to healthy controls in areas beyond the primary lesion, and (c) there might be differences in cortical reorganization after stroke beyond primary lesion, all contributing to the amount of recovery. Higher contralesional sensory-motor gray matter density was furthermore associated with improved motor ability (Gauthier et al., 2012). The study by Gauthier et al. enrolled subjects with up to 20 years chronic stroke phase. However, it is not clear, if patients with a higher contralateral gray matter density before the stroke have better motor outcomes after stroke or if this is a plastic effect related to stroke. Beyond the loss of gray matter as reflected in cortical thickness, stroke results in white matter loss that could influence remote functional networks via Wallerian degeneration (Wang et al., 2016). Loss of myelin in the precentral gyrus might play a crucial role in terms of functional recovery (Dubbioso et al., 2021).

Contralesional thickening in cortical areas beyond primary motor and sensory areas (i.e., OFC and SMC) was associated with improved motor recovery (Liu et al., 2015; Cai et al., 2016). Both studies were longitudinal and imply structural reorganization in contralesional areas beyond primary sensory-motor cortex. In one study decreased contralesional cerebellum thickness was correlated with worse motor recovery (Yu et al., 2017).

The remaining studies did not find an association between functional recovery and cortical thickness, although they have found changes in cortical thickness (Kraemer et al., 2004; Cheng et al., 2015, 2020; Jones et al., 2016; Buetefisch et al., 2018; Liu et al., 2020). Liu et al. (2020), while longitudinally evidenced CT increase ipsi- and contralesionally, did not find correlation with motor improvement. The authors hypothesize that this could possibly be due to the assessment scale they used. In fact, the FMA score represents a general assessment of limb function, and not accurately reflects changes in cognitive functions, which might be indirectly linked to stroke recovery. A relevant number of studies reviewed here, in fact, found a cortical thinning of the ipsilateral primary motor cortex (Gauthier et al., 2012; Liu et al., 2015; Cai et al., 2016; Jones et al., 2016; Yu et al., 2017; Buetefisch et al., 2018).

While the studies included here provide evidence of CT change due to stroke and a possible relationship with clinical outcome, the literature shows remarkable heterogeneities with respect to: patients' sample size $(\mathrm{min} / \mathrm{max}=10 / 85$ patients, median $=18$ patients), stroke location (purely subcortical vs. cortical \& subcortical), study design (longitudinal, case control, randomized controlled trial), data analysis pipeline (voxel-based morphometry, surface-based analysis), and different magnetic field strength for MRI (2 1.5 Tesla, 93 Tesla, 1 mixed; please also check Table 1 for further details).

It is well-known that brain damage following a stroke is certainly the first cause of the complex sequelae occurring, but it is not the only factor defining the level of impairment so that long-term outcome depends upon lesion size and site, structural 
and functional reserve, and genetic pattern (Di Pino et al., 2014, 2016; Di Lazzaro et al., 2015, 2016b). Although studies in acute stroke report a correlation between lesion size and motor deficit, these deficits decrease in the chronic phase of stroke (Gauthier et al., 2012).

\section{Cortical Thinning and Its Possible Mechanisms}

Some studies showed that the effect of the stroke lesion goes far beyond the motor system and the ipsilateral hemisphere, also involving the contralateral side (Cheng et al., 2015, 2020; Liu et al., 2015, 2020; Cai et al., 2016; Yu et al., 2017). In one of the studies examined (Cheng et al., 2020) the concept of "transcallosal diaschisis" was proposed to explain the cortical atrophy of contralateral homologous areas. It was suggested that isolated subcortical lesions could induce contralesional cortical degeneration through interneurons located at the ipsilateral hemisphere that induce apoptosis following loss of synaptic input (Carrera and Tononi, 2014). Post-stroke Wallerian or retrograde degeneration of fiber tracts originating from or projecting to the ischemic brain area has also been suggested as explanation of secondary atrophy (Kraemer et al., 2004; Cai et al., 2016; Cheng et al., 2020).

An alternative perspective on the mechanisms sustaining post-stroke changes in cortical thickness relates to the socalled "non-use cortical atrophy" corresponding to the effects of functional under-activation of primary and secondary motor areas due to motor impairment (Kraemer et al., 2004; Liu et al., 2015; Cheng et al., 2020).

\section{Cortical Thickening and Its Possible Mechanisms}

A few studies have highlighted the presence of thickening of areas beyond the lesion site (Gauthier et al., 2012; Sterr et al., 2013; Liu et al., 2015, 2020; Cai et al., 2016; Yu et al., 2017), typically in the supplementary motor areas of the unaffected hemisphere. Interestingly, one of the studies included here found cortical thickening in the contralateral premotor cortex and supplementary motor area and a better motor performance for those having higher cortical thickness. Beyond their implication in fine motor planning and control, premotor and supplementary motor areas are remarkably involved in cognition at large (Tombini et al., 2009; Pellegrino et al., 2018c; Zangrandi et al., 2019), presumably highlighting how cognitive abilities are important for recovery of the motor function (Liu et al., 2015).

While this finding is not consistent over studies, it would be compatible with models predicting a variation of function (thereby structure) from regions that are spared from the stroke, and progressively work to compensate for the deficit. Animal studies support this hypothesis and have demonstrated that structural changes in neural cells such as increased neuronal sprouting, synaptogenesis as well as in non-neural elements (i.e., increase in glial cells and angiogenesis) occur over a period ranging from weeks to months after stroke (Liu et al., 2015). Moreover, a TMS experiment suggests that microglia play a crucial role in synaptic plasticity (Eichler et al., 2021). While remote neurones may degenerate secondarily to stroke due to a lack of structural connection and underuse, the targeted training of motor areas contralateral to the dominant hand has been shown to result in an increase in cortical thickness and cortical excitability (Sale et al., 2017).

TMS as stroke therapy has been applied to increase ipsilesional excitability or decreases contralesional excitability, addressing brain areas distant from the primary lesion. Processes of longterm potentiation or depression might be reflected in measures of brain structure and cortical thickness (Hebb, 2005; Dubbioso et al., 2015; Raffin et al., 2015; Smith and Stinear, 2016).

Correlations between CT changes and functional recovery were also seen in the study by Gauthier et al. (2012). Here gray matter density of areas beyond the infarct and involved in motor function, vision and cognition, positively correlated with clinical improvement suggesting an effect on more distributed neural networks, which together contributed to motor recovery in chronic stroke. When a correlation between structural changes and function was observed, cortical thinning, localized both ipsilaterally and contralaterally, was associated with worse recovery.

Additionally, motor function recovery was better for those having less cortical thinning in the ipsilateral motor area and cortical thickening in the contralateral areas (Liu et al., 2015). Not only cortical regions beyond the lesion change their structure and are relevant to recovery, indeed the degree of stroke recovery was negatively associated with contralesional cerebellar anterior lobule atrophy (Yu et al., 2017), which is associated to the ipsilesional motor cortex.

\section{Cortical Thickness as Clinical Marker}

While this systematic review included all studies investigating the relationship between changes in structure and clinical sensorymotor outcome, the study situation remains inconclusive and is quite sparse. Stroke rehabilitation primarily aims at mitigating the clinical sequelae and restoring independence in activities of daily living (Langhorne et al., 2011). It focuses on techniques and strategies that can assess brain function and interfere with it (Cramer, 2004, 2008; Cramer et al., 2011; Pellegrino et al., 2012, 2018b). Furthermore, brain imaging and brain stimulation can be combined to achieve a temporally and spatially resolved investigation and interference with brain function (Giambattistelli et al., 2014; Assenza et al., 2015; Pellegrino et al., 2016a,b, 2018a,b, 2019b, 2021; Capone et al., 2017). Despite these advancements, there has been very little success in addressing and harnessing stroke recovery with neuroimaging techniques in clinical practice, most often because of their complexity and monetary costs in a real-life clinical setting beyond clinical research (Di Pino et al., 2014; Assenza et al., 2017; Gramigna et al., 2017; Machado et al., 2018; Cai et al., 2021). An exception is represented by structural MRI, which has entered clinical practice. Virtually all stroke patients without contraindications undergo an MRI with standard sequences, typically T1-weighted, T2-weighted, FLAIR and DWI (Masdeu et al., 2006; Jiang et al., 2010). Clinical data derived from structural MRI, if properly acquired and quantitatively analyzed, 
may contain precious information to better understand plasticity phenomena in stroke patients and provide hints about the clinical status and recovery from early stage after stroke as well as guide the rehabilitation strategy (Jiang et al., 2010).

This systematic review reveals that, as of now, only few studies addressed the relationship between CT beyond primary stroke lesion and sensory-motor outcome. While a huge corpus of studies exists investigating structure-function relationships e.g., in healthy aging subjects (Oschwald et al., 2019) or schizophrenic patients (Birur et al., 2017), the influence of CT secondary to stroke are poorly understood and require more attention, as well, as more systematic research in order to detect patterns of plasticity that might be indicative for recovery.

\section{CONCLUSIONS}

The aim of this paper was to conduct a systematic review on the existing literature exploring changes in CT after stroke in regions beyond the main lesion and their potential relationships with functional recovery. We hypothesized that cortical changes beyond the lesion would occur, as predicted in animal models and human stroke models. Whether clinical outcome is associated with thinning of lesioned regions and connected areas or compensatory thickening of distant areas remains not properly investigated yet. There is evidence that, following a stroke, changes in CT occur both in regions directly connected to the main stroke lesion but also in the contralateral homologs and in the cerebellum. It has been hypothesized that anterograde and retrograde degeneration may explain these phenomena, but also metabolic changes may play a role. The studies performed so far are limited with regards to population type, sample size, procedure utilized to analyze data and to report results. Nonetheless, the importance of these results supporting the occurrence of structural plastic phenomena beyond the stroke lesion and their role in clinical outcome should not be underestimated. Further studies on

\section{REFERENCES}

Adhikari, M. H., Hacker, C. D., Siegel, J. S., Griffa, A., Hagmann, P., Deco, G., et al. (2017). Decreased integration and information capacity in stroke measured by whole brain models of resting state activity. Brain 140, 1068-1085. doi: 10.1093/brain/awx021

Assenza, G., Campana, C., Assenza, F., Pellegrino, G., Di Pino, G., Fabrizio, E., et al. (2017). Cathodal transcranial direct current stimulation reduces seizure frequency in adults with drug-resistant temporal lobe epilepsy: A sham controlled study. Brain Stimul. 10, 333-335. doi: 10.1016/j.brs.2016.12.005

Assenza, G., Pellegrino, G., Tombini, M., Di Pino, G., and Di Lazzaro, V. (2015). Wakefulness delta waves increase after cortical plasticity induction. Clin. Neurophysiol. 126, 1221-1227. doi: 10.1016/j.clinph.2014.09.029

Barber, P. A., Darby, D. G., Desmond, P. M., Yang, Q., Gerraty, R. P., Jolley, D., et al. (1998). Prediction of stroke outcome with echoplanar perfusion- and diffusion-weighted MRI. Neurology 51, 418-426. doi: 10.1212/wnl.51.2.418

Beaulieu, C., Crespigny, A. D., Tong, D. C., Moseley, M. E., Albers, G. W., and Marks, M. P. (1999). Longitudinal magnetic resonance imaging study of perfusion and diffusion in stroke: Evolution of lesion volume and correlation with clinical outcome. Ann. Neurol. 46, 568-578. doi: 10.1002/1531-8249(199910)46:4<568::AID-ANA4>3.0.CO;2-R

Bernhardt, J., Hayward, K. S., Kwakkel, G., Ward, N. S., Wolf, S. L., Borschmann, K., et al. (2017). Agreed definitions and a shared vision for new standards in larger patient samples need to be performed, taking into consideration a more comprehensive clinical assessment and addressing the positive/negative effects of different rehabilitation procedures. While such studies may appear demanding, their implementation could be easier, if accompanied by the improvement and standardization of clinical MRI acquisition procedures (volumetric acquisitions of T1-weighted images with good spatial resolution).

\section{DATA AVAILABILITY STATEMENT}

The original contributions presented in the study are included in the article/Supplementary Material, further inquiries can be directed to the corresponding author/s.

\section{AUTHOR CONTRIBUTIONS}

AC, LC, AT, and GP contributed to conception and design of the study. AC and LC performed data screening, extraction, and wrote the first draft of the manuscript. A-LS, AT, and GP wrote sections of the manuscript. AT performed data screening. All authors contributed to manuscript revision, read, and approved the submitted version.

\section{FUNDING}

AC was supported by the Italian Ministry of Health Grant no. GR-2018-12367485. AT was supported by the Italian Ministry of Health Grant no. RF-2019-12371486. GP was supported by the Italian Ministry of Health Grant no. GR-2019-12368960.

\section{SUPPLEMENTARY MATERIAL}

The Supplementary Material for this article can be found online at: https://www.frontiersin.org/articles/10.3389/fnins. 2021.764671/full\#supplementary-material

stroke recovery research: The Stroke Recovery and Rehabilitation Roundtable taskforce. Int. J. Stroke 12, 444-450. doi: 10.1177/1747493017711816

Birur, B., Kraguljac, N. V., Shelton, R. C., and Lahti, A. C. (2017). Brain structure, function, and neurochemistry in schizophrenia and bipolar disorder-a systematic review of the magnetic resonance neuroimaging literature. NPJ Schizophr 3:15. doi: 10.1038/s41537-017-0013-9

Brodtmann, A., Pardoe, H., Li, Q., Lichter, R., Ostergaard, L., and Cumming, T. (2012). Changes in regional brain volume three months after stroke. J. Neurol. Sci. 322, 122-128. doi: 10.1016/j.jns.2012.07.019

Buetefisch, C. M., Revill, K. P., Haut, M. W., Kowalski, G. M., Wischnewski, M., Pifer, M., et al. (2018). Abnormally reduced primary motor cortex output is related to impaired hand function in chronic stroke. J. Neurophysiol. 120, 1680-1694. doi: 10.1152/jn.00715.2017

Burke Quinlan, E., Dodakian, L., See, J., McKenzie, A., Le, V., Wojnowicz, M., et al. (2015). Neural function, injury, and stroke subtype predict treatment gains after stroke: Predicting Gains after Stroke. Ann. Neurol. 77, 132-145. doi: 10.1002/ana.24309

Cai, J., Ji, Q., Xin, R., Zhang, D., Na, X., Peng, R., et al. (2016). Contralesional cortical structural reorganization contributes to motor recovery after subcortical stroke: a longitudinal voxel-based morphometry study. Front. Hum. Neurosci. 10:393. doi: 10.3389/fnhum.2016.00393

Cai, Z., Uji, M., Aydin, Ü., Pellegrino, G., Spilkin, A., Delaire, É., et al. (2021). Evaluation of a personalized functional near INFRA-RED optical tomography 
workflow using maximum entropy on the mean. Hum. Brain Mapp. 42, 4823-4843. doi: 10.1002/hbm.25566

Capone, F., Miccinilli, S., Pellegrino, G., Zollo, L., Simonetti, D., Bressi, F., et al. (2017). Transcutaneous vagus nerve stimulation combined with robotic rehabilitation improves upper limb function after stroke. Neural Plast. 2017, 1-6. doi: 10.1155/2017/7876507

Carrera, E., and Tononi, G. (2014). Diaschisis: past, present, future. Brain 137, 2408-2422. doi: 10.1093/brain/awu101

Chen, C.-L., Tang, F.-T., Chen, H.-C., Chung, C.-Y., and Wong, M.-K. (2000). Brain lesion size and location: Effects on motor recovery and functional outcome in stroke patients. Arch. Phys. Med. Rehabil. 81, 447-452. doi: $10.1053 / \mathrm{mr} .2000 .3837$

Chen, L., Luo, T., Wang, K., Zhang, Y., Shi, D., Lv, F., et al. (2019). Effects of thalamic infarction on the structural and functional connectivity of the ipsilesional primary somatosensory cortex. Eur. Radiol. 29, 4904-4913. doi: 10.1007/s00330-019-06068-0

Cheng, B., Dietzmann, P., Schulz, R., Boenstrup, M., Krawinkel, L., Fiehler, J., et al. (2020). Cortical atrophy and transcallosal diaschisis following isolated subcortical stroke. J. Cereb. Blood Flow Metabo. 40, 611-621. doi: 10.1177/0271678X19831583

Cheng, B., Schulz, R., Bönstrup, M., Hummel, F. C., Sedlacik, J., Fiehler, J., et al. (2015). Structural plasticity of remote cortical brain regions is determined by connectivity to the primary lesion in subcortical stroke. J. Cereb. Blood Flow Metabo. 35, 1507-1514. doi: 10.1038/jcbfm.2015.74

Cirstea, C. M., Brooks, W. M., Craciunas, S. C., Popescu, E. A., Choi, I. Y., Lee, P., et al. (2011). Primary motor cortex in stroke: a functional MRI-guided proton MR spectroscopic study. Stroke 42, 1004-1009. doi: 10.1161/STROKEAHA.110.601047

Cirstea, C. M., Nudo, R. J., Craciunas, S. C., Popescu, E. A., Choi, I. Y., Lee, P., et al. (2012). Neuronal-glial alterations in non-primary motor areas in chronic subcortical stroke. Brain Res. 1463, 75-84. doi: 10.1016/j.brainres.2012.04.052

Cramer, S. C. (2004). Functional imaging in stroke recovery. Stroke 35, 2695-2698. doi: 10.1161/01.STR.0000143326.36847.b0

Cramer, S. C. (2008). Repairing the human brain after stroke: I. Mechanisms of spontaneous recovery. Ann. Neurol. 63, 272-287. doi: 10.1002/ana.21393

Cramer, S. C., Sur, M., Dobkin, B. H., O’Brien, C., Sanger, T. D., Trojanowski, J. Q., et al. (2011). Harnessing neuroplasticity for clinical applications. Brain 134, 1591-1609. doi: 10.1093/brain/awr039

Cumpston, M., Li, T., Page, M. J., Chandler, J., Welch, V. A., Higgins, J. P., et al. (2019). Updated guidance for trusted systematic reviews: a new edition of the Cochrane Handbook for Systematic Reviews of Interventions. Cochrane Datab. Syst. Rev. 10:ED000142. doi: 10.1002/14651858.ED000142

Dale, A. M., Fischl, B., and Sereno, M. I. (1999). Cortical surface-based analysis. I. Segmentation and surface reconstruction. Neuroimage 9, 179-194. doi: 10.1006/nimg.1998.0395

Di Lazzaro, V., Capone, F., Di Pino, G., Pellegrino, G., Florio, L., Zollo, L., et al. (2016a). Combining robotic training and non-invasive brain stimulation in severe upper limb-impaired chronic stroke patients. Front. Neurosci. 10:88. doi: 10.3389/fnins.2016.00088

Di Lazzaro, V., Dileone, M., Capone, F., Pellegrino, G., Ranieri, F., Musumeci, G., et al. (2014). Immediate and late modulation of interhemipheric imbalance with bilateral transcranial direct current stimulation in acute stroke. Brain Stimul. 7, 841-848. doi: 10.1016/j.brs.2014.10.001

Di Lazzaro, V., Pellegrino, G., Di Pino, G., Corbetto, M., Ranieri, F., Brunelli, N., et al. (2015). Val66Met BDNF gene polymorphism influences human motor cortex plasticity in acute stroke. Brain Stimul. 8, 92-96. doi: 10.1016/j.brs.2014.08.006

Di Lazzaro, V., Pellegrino, G., Di Pino, G., Ranieri, F., Lotti, F., Florio, L., et al. (2016b). Human motor cortex functional changes in acute stroke: gender effects. Front. Neurosci. 10:10. doi: 10.3389/fnins.2016.00010

Di Pino, G., Pellegrino, G., Assenza, G., Capone, F., Ferreri, F., Formica, D., et al. (2014). Modulation of brain plasticity in stroke: a novel model for neurorehabilitation. Nat. Rev. Neurol. 10, 597-608. doi: 10.1038/nrneurol.2014.162

Di Pino, G., Pellegrino, G., Capone, F., Assenza, G., Florio, L., Falato, E., et al. (2016). Val66Met BDNF polymorphism implies a different way to recover from stroke rather than a worse overall recoverability. Neurorehabil. Neural Repair 30, 3-8. doi: 10.1177/1545968315583721
Dobkin, B. H. (2005). Rehabilitation after stroke. N. Engl. J. Med. 352, 1677-1684. doi: 10.1056/NEJMcp043511

Dodd, K. C., Nair, V. A., and Prabhakaran, V. (2017). Role of the contralesional vs. ipsilesional hemisphere in stroke recovery. Front. Hum. Neurosci. 11:469. doi: 10.3389/fnhum.2017.00469

Dromerick, A. W., and Reding, M. J. (1995). Functional outcome for patients with hemiparesis, hemihypesthesia, and hemianopsia. Does lesion location matter? Stroke 26, 2023-2026. doi: 10.1161/01.str.26.11.2023

Dubbioso, R., Madsen, K. H., Thielscher, A., and Siebner, H. R. (2021). The myelin content of the human precentral hand knob reflects interindividual differences in manual motor control at the physiological and behavioral level. J. Neurosci. 41, 3163-3179. doi: 10.1523/JNEUROSCI.0390-20.2021

Dubbioso, R., Pellegrino, G., Antenora, A., De Michele, G., Filla, A., Santoro, L., et al. (2015). The effect of cerebellar degeneration on human sensori-motor plasticity. Brain Stimul. 8, 1144-1150. doi: 10.1016/j.brs.2015.05.012

Duering, M., Righart, R., Wollenweber, F. A., Zietemann, V., Gesierich, B., and Dichgans, M. (2015). Acute infarcts cause focal thinning in remote cortex via degeneration of connecting fiber tracts. Neurology 84, 1685-1692. doi: 10.1212/WNL.0000000000001502

Eichler, A., Kleidonas, D., Turi, Z., Kirsch, M., Pfeifer, D., Masuda, T., et al. (2021). Microglia mediate synaptic plasticity induced by $10 \mathrm{~Hz}$ repetitive magnetic stimulation. bioRxiv [preprint]. doi: 10.1101/2021.10.03.462905

Ernst, M., Boers, A. M. M., Forkert, N. D., Berkhemer, O. A., Roos, Y. B., Dippel, D. W. J., et al. (2018). Impact of ischemic lesion location on the mrs score in patients with ischemic stroke: a voxel-based approach. AJNR Am. J. Neuroradiol. 39, 1989-1994. doi: 10.3174/ajnr.A5821

Gauthier, L. V., Taub, E., Mark, V. W., Barghi, A., and Uswatte, G. (2012). Atrophy of spared gray matter tissue predicts poorer motor recovery and rehabilitation response in chronic stroke. Stroke 43, 453-457. doi: 10.1161/STROKEAHA.111.633255

Giambattistelli, F., Tomasevic, L., Pellegrino, G., Porcaro, C., Melgari, J. M., Rossini, P. M., et al. (2014). The spontaneous fluctuation of the excitability of a single node modulates the internodes connectivity: a TMS-EEG study. Hum. Brain Mapp. 35, 1740-1749. doi: 10.1002/hbm.22288

Gramigna, V., Pellegrino, G., Cerasa, A., Cutini, S., Vasta, R., Olivadese, G., et al. (2017). Near-infrared spectroscopy in gait disorders: is it time to begin? Neurorehabil. Neural Repair 31, 402-412. doi: 10.1177/1545968317693304

Hebb, D. O. (2005). The Organization of Behavior: A Neuropsychological Theory. New York, NY: Psychology Press.

Jiang, Q., Zhang, Z. G., and Chopp, M. (2010). MRI of stroke recovery. Stroke 41, 410-414. doi: 10.1161/STROKEAHA.109.568048

Jones, P. W., Borich, M. R., Vavsour, I., Mackay, A., and Boyd, L. A. (2016). Cortical thickness and metabolite concentration in chronic stroke and the relationship with motor function. Restor. Neurol. Neurosci. 34, 733-746. doi: $10.3233 / \mathrm{RNN}-150623$

Kraemer, M., Schormann, T., Hagemann, G., Qi, B., Witte, O. W., and Seitz, R. J. (2004). Delayed shrinkage of the brain after ischemic stroke: preliminary observations with voxel-guided morphometry. J. Neuroimaging 14, 265-272. doi: 10.1177/1051228404264950

Langhorne, P., Bernhardt, J., and Kwakkel, G. (2011). Stroke rehabilitation. Lancet 377, 1693-1702. doi: 10.1016/S0140-6736(11)60325-5

Liu, G., Dang, C., Peng, K., Xie, C., Chen, H., Xing, S., et al. (2015). Increased spontaneous neuronal activity in structurally damaged cortex is correlated with early motor recovery in patients with subcortical infarction. Eur. J. Neurol. 22 1540-1547. doi: 10.1111/ene.12780

Liu, H., Peng, X., Dahmani, L., Wang, H., Zhang, M., Shan, Y., et al. (2020). Patterns of motor recovery and structural neuroplasticity after striatal infarcts. Neurology 95:10149. doi: 10.1212/WNL.0000000000010149

Löuvbld, K.-O., Baird, A. E., Schlaug, G., Benfield, A., Siewert, B., Voetsch, B., et al. (1997). Ischemic lesion volumes in acute stroke by diffusion-weighted magnetic resonance imaging correlate with clinical outcome. Ann. Neurol. 42, 164-170. doi: 10.1002/ana.410420206

Machado, A., Cai, Z., Pellegrino, G., Marcotte, O., Vincent, T., Lina, J.-M., et al. (2018). Optimal positioning of optodes on the scalp for personalized functional near-infrared spectroscopy investigations. J. Neurosci. Methods 309, 91-108. doi: 10.1016/j.jneumeth.2018.08.006

Masdeu, J. C., Irimia, P., Asenbaum, S., Bogousslavsky, J., Brainin, M., Chabriat, H., et al. (2006). EFNS guideline on neuroimaging in acute 
stroke. Report of an EFNS task force. Eur. J. Neurol. 13, 1271-1283. doi: 10.1111/j.1468-1331.2006.01507.x

Miyai, I., Blau, A. D., Reding, M., and Volpe, B. T. (1997). Patients with stroke confined to basal ganglia have diminished response to rehabilitation efforts. Neurology 48, 95-101.

Moher, D., Liberati, A., Tetzlaff, J., Altman, D. G., and Group, T. P. (2009). Preferred reporting items for systematic reviews and meta-analyses: The PRISMA Statement. PLoS Med. 6:e1000097. doi: 10.1371/journal.pmed.1000097

Munsch, F., Sagnier, S., Asselineau, J., Bigourdan, A., Guttmann, C., R., et al. (2016). Stroke location is an independent predictor of cognitive outcome. Stroke 47, 66-73. doi: 10.1161/STROKEAHA.115.011242

Murphy, T. H., and Corbett, D. (2009). Plasticity during stroke recovery: from synapse to behaviour. Nat. Rev. Neurosci. 10, 861-872. doi: 10.1038/nrn2735

Oschwald, J., Guye, S., Liem, F., Rast, P., Willis, S., Röcke, C., et al. (2019). Brain structure and cognitive ability in healthy aging: a review on longitudinal correlated change. Rev. Neurosci. 31, 1-57. doi: 10.1515/revneuro-2018-0096

Ouzzani, M., Hammady, H., Fedorowicz, Z., and Elmagarmid, A. (2016). Rayyan-a web and mobile app for systematic reviews. Syste. Rev. 5:384. doi: 10.1186/s13643-016-0384-4

Pantano, P., Formisano, R., Ricci, M., Di Piero, V., Sabatini, U., Di Pofi, B., et al. (1996). Motor recovery after stroke. Morphological and functional brain alterations. Brain 119, 1849-1857. doi: 10.1093/brain/119.6.1849

Pellegrino, G., Arcara, G., Cortese, A. M., Weis, L., Di Tomasso, S., Marioni, G., et al. (2019a). Cortical gamma-synchrony measured with magnetoencephalography is a marker of clinical status and predicts clinical outcome in stroke survivors. NeuroImage: Clin. 24:102092. doi: 10.1016/j.nicl.2019.102092

Pellegrino, G., Arcara, G., Di Pino, G., Turco, C., Maran, M., Weis, L., et al. (2019b). Transcranial direct current stimulation over the sensory-motor regions inhibits gamma synchrony. Hum. Brain Mapp. 40, 2736-2746. doi: 10.1002/hbm. 24556

Pellegrino, G., Hedrich, T., Chowdhury, R., Hall, J. A., Lina, J. M., Dubeau, F., et al. (2016a). Source localization of the seizure onset zone from ictal EEG/MEG data. Hum. Brain Mapp. 37, 2528-2546. doi: 10.1002/hbm.23191

Pellegrino, G., Hedrich, T., Chowdhury, R. A., Hall, J. A., Dubeau, F., Lina, J. M., et al. (2018a). Clinical yield of magnetoencephalography distributed source imaging in epilepsy: A comparison with equivalent current dipole method. Hum. Brain Mapp. 39, 218-231. doi: 10.1002/hbm.23837

Pellegrino, G., Hedrich, T., Sziklas, V., Lina, J., Grova, C., and Kobayashi, E. (2021). How cerebral cortex protects itself from interictal spikes: The alpha/beta inhibition mechanism. Hum. Brain Mapp. 42, 3352-3365. doi: $10.1002 / \mathrm{hbm} .25422$

Pellegrino, G., Machado, A., von Ellenrieder, N., Watanabe, S., Hall, J. A., Lina, J. M., et al. (2016b). hemodynamic response to interictal epileptiform discharges addressed by personalized EEG-fNIRS recordings. Front. Neurosci. 10:102. doi: $10.3389 /$ fnins. 2016.00102

Pellegrino, G., Maran, M., Turco, C., Weis, L., Di Pino, G., Piccione, F., et al. (2018b). Bilateral transcranial direct current stimulation reshapes restingstate brain networks: a magnetoencephalography assessment. Neural Plast. 2018:2782804. doi: 10.1155/2018/2782804

Pellegrino, G., Tomasevic, L., Herz, D. M., Larsen, K. M., and Siebner, H. R. (2018c). Theta Activity in the Left Dorsal Premotor Cortex During Action Re-Evaluation and Motor Reprogramming. Front. Hum. Neurosci. 12, 364. doi: $10.3389 /$ fnhum.2018.00364

Pellegrino, G., Tomasevic, L., Tombini, M., Assenza, G., Bravi, M., Sterzi, S., et al. (2012). Inter-hemispheric coupling changes associate with motor improvements after robotic stroke rehabilitation. Restor. Neurol. Neurosci. 30, 497-510. doi: 10.3233/RNN-2012-120227

Raffin, E., Pellegrino, G., Di Lazzaro, V., Thielscher, A., and Siebner, H. R. (2015). Bringing transcranial mapping into shape: Sulcusaligned mapping captures motor somatotopy in human primary motor hand area. Neuroimage 120, 164-175. doi: 10.1016/j.neuroimage.2015. 07.024

Sale, M. V., Reid, L. B., Cocchi, L., Pagnozzi, A. M., Rose, S. E., and Mattingley, J. B. (2017). Brain changes following four weeks of unimanual motor training: Evidence from behavior, neural stimulation, cortical thickness, and functional MRI. Hum. Brain Mapp. 38, 4773-4787. doi: 10.1002/hbm.23710
Siegel, J. S., Seitzman, B. A., Ramsey, L. E., Ortega, M., Gordon, E. M., Dosenbach, N. U. F., et al. (2018). Re-emergence of modular brain networks in stroke recovery. Cortex 101, 44-59. doi: 10.1016/j.cortex.2017.12.019

Silasi, G., and Murphy, T. H. (2014). Stroke and the connectome: how connectivity guides therapeutic intervention. Neuron 83, 1354-1368. doi: 10.1016/j.neuron.2014.08.052

Smith, M.-C., and Stinear, C. M. (2016). Transcranial magnetic stimulation (TMS) in stroke: ready for clinical practice? J. Clin. Neurosci. 31, 10-14. doi: 10.1016/j.jocn.2016.01.034

Stang, A. (2010). Critical evaluation of the Newcastle-Ottawa scale for the assessment of the quality of nonrandomized studies in meta-analyses. Eur. J. Epidemiol. 25, 603-605. doi: 10.1007/s10654-010-9491-z

Sterr, A., Dean, P. J. A., Vieira, G., Conforto, A. B., Shen, S., and Sato, J. R. (2013). Cortical thickness changes in the non-lesioned hemisphere associated with non-paretic arm immobilization in modified CI therapy. NeuroImage: Clin. 2, 797-803. doi: 10.1016/j.nicl.2013.05.005

Streitbürger, D.-P., Möller, H. E., Tittgemeyer, M., Hund-Georgiadis, M., Schroeter, M. L., and Mueller, K. (2012). Investigating structural brain changes of dehydration using voxel-based morphometry. PLoS ONE 7:e44195. doi: 10.1371/journal.pone.0044195

Tombini, M., Zappasodi, F., Zollo, L., Pellegrino, G., Cavallo, G., Tecchio, F., et al. (2009). Brain activity preceding a 2D manual catching task. Neuroimage 47 , 1735-1746. doi: 10.1016/j.neuroimage.2009.04.046

Vogt, G., Laage, R., Shuaib, A., and Schneider, A. (2012). Initial lesion volume is an independent predictor of clinical stroke outcome at day 90. Stroke 43, 1266-1272. doi: 10.1161/STROKEAHA.111.646570

Vos, T., Allen, C., Arora, M., Barber, R. M., Bhutta, Z. A., Brown, A., et al. (2016). Global, regional, and national incidence, prevalence, and years lived with disability for 310 diseases and injuries, 1990-2015: a systematic analysis for the Global Burden of Disease Study 2015. Lancet 388, 1545-1602. doi: 10.1016/S0140-6736(18)32279-7

Wang, Y., Liu, G., Hong, D., Chen, F., Ji, X., and Cao, G. (2016). White matter injury in ischemic stroke. Prog. Neurobiol. 141, 45-60. doi: 10.1016/j.pneurobio.2016.04.005

Werden, E., Cumming, T., Li, Q., Bird, L., Veldsman, M., Pardoe, H. R., et al. (2017). Structural MRI markers of brain aging early after ischemic stroke. Neurology 89, 116-124. doi: 10.1212/WNL.0000000000004086

Yu, X., Yang, L., Song, R., Jiaerken, Y., Yang, J., Lou, M., et al. (2017). Changes in structure and perfusion of grey matter tissues during recovery from Ischaemic subcortical stroke: a longitudinal MRI study. Eur. J. Neurosci. 46, 2308-2314. doi: 10.1111/ejn.13669

Zangrandi, A., Mioli, A., D’Alonzo, M., Formica, D., Pellegrino, G., and Di Pino, G. (2019). Conditioning transcranial magnetic stimulation of ventral premotor cortex shortens simple reaction time. Cortex 121, 322-331. doi: 10.1016/j.cortex.2019.09.006

Zhang, J., Meng, L., Qin, W., Liu, N., Shi, F.-D., and Yu, C. (2014). Structural damage and functional reorganization in ipsilesional M1 in well-recovered patients with subcortical stroke. Stroke 45, 788-793. doi: 10.1161/STROKEAHA.113.003425

Conflict of Interest: The authors declare that the research was conducted in the absence of any commercial or financial relationships that could be construed as a potential conflict of interest.

Publisher's Note: All claims expressed in this article are solely those of the authors and do not necessarily represent those of their affiliated organizations, or those of the publisher, the editors and the reviewers. Any product that may be evaluated in this article, or claim that may be made by its manufacturer, is not guaranteed or endorsed by the publisher.

Copyright $\odot 2021$ Cortese, Cacciante, Schuler, Turolla and Pellegrino. This is an open-access article distributed under the terms of the Creative Commons Attribution License (CC BY). The use, distribution or reproduction in other forums is permitted, provided the original author(s) and the copyright owner(s) are credited and that the original publication in this journal is cited, in accordance with accepted academic practice. No use, distribution or reproduction is permitted which does not comply with these terms. 